\title{
Effect of favipiravir and an anti- inflammatory strategy for COVID-19
}

Hitoshi Yamamura ${ }^{*}$ (D), Hiroshi Matsuura, Junichiro Nakagawa, Hiroshi Fukuoka, Hisaya Domi and Satoru Chujoh

Keywords: Favipiravir, Inflammatory, Cytokine

Favipiravir (T-705; 6-fluoro-3-hydroxy-2-pyrazinecarboxamide) is an anti-viral agent that selectively and potently inhibits the ribonucleic acid (RNA)-dependent RNA polymerase of RNA viruses [1]. In Japan, it is approved for use with novel influenza virus and is thought to be an effective drug for severe acute respiratory syndrome coronavirus 2 (SARS-CoV-2). Coronavirus disease 2019 (COVID-19) presents a complex pathology including inflammation, endothelial damage, thrombus formation, and acute respiratory failure [2-4] This syndrome requires complex treatment to reduce viral genome amounts, antiinflammatory drugs, and anticoagulation. We attempted the cocktail treatment of favipiravir, steroid, and heparin for COVID-19. This study aimed to evaluate the effect of cocktail therapy for severe COVID-19.

This prospective, single-center study was conducted on all patients admitted to our hospital by transfer from other hospitals who required mechanical ventilation for severe COVID-19 between April 2 and 27, 2020. COVID-19 was diagnosed with real-time reverse transcriptase-polymerase chain reaction in approved laboratories from nasopharyngeal and throat swabs and with lung computed tomography. The treatment protocol was as follows: oral favipiravir (3600 $\mathrm{mg}$ on day $1,1600 \mathrm{mg}$ from day 2 to day 14), methylprednisolone (1000 $\mathrm{mg}$ for 3 days), and low molecular weight (2000 IU every $12 \mathrm{~h}$ ) or unfractionated heparin (10,000-12,000 IU/day). Methylprednisolone administration was begun on the 5th day from initial favipiravir administration. Heparin and dexmedetomidine were administered after intubation and mechanical ventilation

\footnotetext{
* Correspondence: yamamura@nmcam.jp

Osaka Prefectural Nakakawachi Emergency and Critical Care Center, 3-4-13 Nishiiwata, Higashiosaka, Osaka 578-0947, Japan
}

was started. Wilcoxon signed-rank tests were used to assess patients' changes in paired $\mathrm{PaO}_{2} / \mathrm{FIO}_{2}(\mathrm{P} / \mathrm{F})$ ratio, IL-6, and presepsin. All statistical analyses were performed with JMP, Version 13.0.0 (SAS Institute Inc.).

Thirteen patients with COVID-19 requiring mechanical ventilation were admitted during the study period. The treatment protocol was completed without any clinically important change in 2 patients with bronchial asthma, one with rheumatoid arthritis (early-stage steroid administration) and one with bleeding complication (without heparin). Patient characteristics and initial laboratory data are summarized in Table 1. Mean patient age was 63 (range, $46-80$ ) years, and $69.0 \%$ were men. Only one patient required extracorporeal membrane oxygenation. Time from first symptom appearance to favipiravir administration was 8.7 (range, 4-13) days. One patient died due to disseminated intravascular coagulation (DIC) on admission that gradually progressed to multiple organ failure.

The time course of the clinical laboratory data is shown in Fig. 1. Day 1 indicates the first day of favipiravir administration. The P/F ratio changed very little over the first 6 days and then gradually recovered. The interleukin- 6 peaked on day 4 and decreased thereafter. Presepsin also peaked on day 3 , remained about the same until day 6 , and then decreased.

The clinical course of SARS-CoV-2 treatment with the cocktail in mechanically ventilated patients with COVID-19 indicated that favipiravir could partially control inflammatory mediators but could not completely control them or respiratory status. The respiratory distress of SARS-CoV-2 is thought to be due not only to direct viral action but also to chemical mediators induced by SARS-CoV-2. Inflammation and cytokine 
Table 1 Characteristics of 13 patients with COVID-19

\begin{tabular}{|c|c|}
\hline Characteristics & Value \\
\hline Age, mean (SD), years & $63(12)$ \\
\hline Male sex, No. (\%) & $9(69)$ \\
\hline Body weight, mean (SD), kg & $70(21)$ \\
\hline Bronchial asthma No. (\%) & $1(8)$ \\
\hline Diabetes mellitus, No. (\%) & $7(54)$ \\
\hline Hypertension, No. (\%) & $8(62)$ \\
\hline Sleep apnea syndrome, No. (\%) & $3(23)$ \\
\hline APACHE II score, median [IQR] & $9[5,13]$ \\
\hline $\mathrm{PaO}_{2} / \mathrm{FlO}_{2}$ ratio at intubation, mean (SD) & $210(73)$ \\
\hline D-dimer on admission, median [IQR], ng/mL & $1.3[1.0,2.8]$ \\
\hline CRP on admission, median [IQR], mg/dL & $11.9[4.6,19.6]$ \\
\hline PCT on admission, median [IQR], $\mathrm{ng} / \mathrm{mL}$ & $0.21[0.09,0.54]$ \\
\hline Presepsin on admission, median [IQR], pg/mL & $440[302,763]$ \\
\hline IL-6 on admission, median [IQR], pg/mL & $77.5[35.7,161.9]$ \\
\hline \multicolumn{2}{|c|}{ Time from first symptom appearance, mean (SD), day } \\
\hline Favipiravir & $8.7(2.6)$ \\
\hline Heparin & $10.8(3.9)$ \\
\hline Steroid & $13.2(2.9)$ \\
\hline Dexmedetomidine & $10.7(4.1)$ \\
\hline Intubation & $9.9(3.3)$ \\
\hline ECMO, No. (\%) & $1(8)$ \\
\hline Ventilator days, median [IQR], days & $11[9,12]$ \\
\hline \multicolumn{2}{|l|}{ Outcome, No. (\%) } \\
\hline Survived & $12(92)$ \\
\hline Dead & $1(8)$ \\
\hline
\end{tabular}

$S D$ standard deviation, $A P A C H E$ II Acute Physiology and Chronic Health Evaluation $\mathrm{Il}, \mathrm{IQR}$ interquartile range, $\mathrm{PaO}_{2}$ arterial partial pressure of oxygen, $\mathrm{FIO}_{2}$ fraction of inspiratory oxygen, CRP C-reactive protein, $P C T$ procalcitonin, IL-6 interleukin-6, ECMO extracorporeal membrane oxygenation

Continuous variables were reported as median [interquartile range] (IQR). Categorical variables were reported as numbers and percentages 


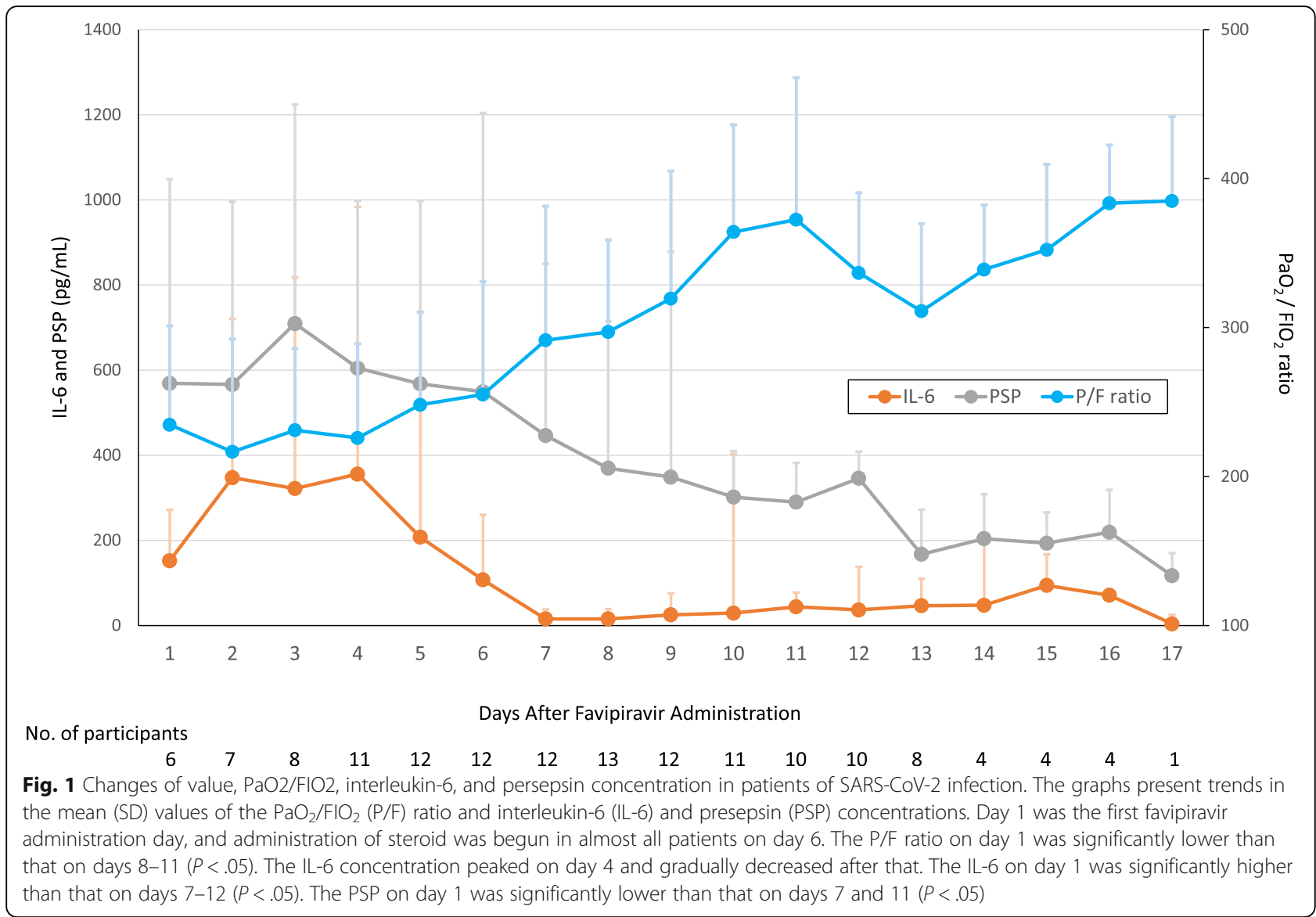

storm continued after favipiravir administration, and they could be controlled with steroid in our patients. Limitations of this study include its small sample size and performance in a single medical center. The start of favipiravir administration was delayed. Steroid therapy has adverse effects, and we did not assess long-term complications [3]. Nevertheless, the results suggested that favipiravir was of some benefit, and the findings helped inform a treatment strategy for severe COVID-19.

\section{Abbreviations}

RNA: Ribonucleic acid; COVID-19: Coronavirus disease 2019; SARS-CoV2: Severe acute respiratory syndrome coronavirus 2; $\mathrm{P} / \mathrm{F}: \mathrm{PaO}_{2} / \mathrm{FIO}_{2}$

\section{Acknowledgements}

None

\section{Authors' contributions}

$\mathrm{HY}, \mathrm{HM}$, and SC are responsible for the conception and design. HY, JN, HD, and $\mathrm{HF}$ analyzed and interpreted the data. $\mathrm{HY}$ and $\mathrm{HM}$ drafted the manuscript. All authors revised the manuscript. All authors approved the final version of the manuscript and agreed to authorship contributions.

\section{Funding}

No funding.

\section{Availability of data and materials}

The datasets generated and/or analyzed during the current study are not publicly available due to institutional policy but are available from the corresponding author on reasonable request.
Ethics approval and consent to participate

All studies were approved by the Ethical Committee of Higashiosaka City Medical Center.

\section{Consent for publication}

Not applicable.

\section{Competing interests}

The authors declare that they have no competing interests.

Received: 6 June 2020 Accepted: 1 July 2020

Published online: 09 July 2020

\section{References}

1. Furuta $Y$, Komeno T, Nakamura T. Favipiravir (T-705), a broad spectrum inhibitor of viral RNA polymerase. Proc Jpn Acad Ser B Phys Biol Sci. 2017; 93(7):449-63.

2. Marini JJ, Gattinoni L. Management of COVID-19 respiratory distress. JAMA. 2020. https://doi.org/10.1001/jama.2020.6825.

3. Mehta P, McAuley DF, Brown M, et al. COVID-19: consider cytokine storm syndromes and immunosuppression. Lancet. 2020:395(10229):1033-4.

4. Grasselli G, Zangrillo A, Zanella A, et al. Baseline characteristics and outcomes of 1591 patients infected with SARS-CoV-2 admitted to ICUs of the Lombardy Region. Italy JAMA. 2020;323(16):1574-81.

\section{Publisher's Note}

Springer Nature remains neutral with regard to jurisdictional claims in published maps and institutional affiliations. 